\section{Chemical Regulators Affect Growth, Postproduction Performance, and Propagation of Golden Pothos}

\author{
Yin-Tung Wang' and Lori L. Gregg ${ }^{2}$ \\ Department of Horticulture, Texas A\&M University Agricultural Research \\ and Extension Center, 2415 East Highway 83, Weslaco, TX 78596
}

\section{Additional index words. Epipremnum aureum}

\begin{abstract}
Drench paclobutrazol or uniconazole applications $(0.1-1.0 \mathrm{mg} / 0.5$-liter pot or 0.05-0.2 $\mathrm{mg} /$ pot, respectively) were effective in suppressing stem elongation of golden pothos [Epipremnum aureum (Linden \& Andrè) Bunt.]. Although the leaf production rate was reduced by both retardants, treated plants produced larger leaves than the controls, resulting in greater total leaf areas. Response to foliar paclobutrazol or uniconazole applications (0-200 and 0-100 mg.liter ${ }^{-1}$, respectively) was similar to the soil drench patterns, except that the leaf production rate was unaffected. Following 10 weeks in an interior environment, plants previously treated with either retardant produced shorter stems, fewer but larger leaves, and lower fresh weights than the nontreated plants. Cuttings collected from stock plants previously treated with a paclobutrazol or uniconazole soil drench $(0.1$ or $0.05 \mathrm{mg} / 0.5$-liter pot, respectively) produced longer stemmed shoots, more and larger leaves, and heavier shoot fresh weights than cuttings from the nontreated plants. Foliar paclobutrazol application $\left(0-200 \mathrm{mg}^{-} \cdot \mathrm{liter}^{-1}\right)$ to stock plants resulted in cuttings producing larger leaves and heavier shoot fresh weights than controls. Chemical names used: (2RS,3RS)-1-(4-chlorophenyl)-4,-4-dlmethyl-2-(1,2,4-trizol-l-yl)pentin-3-ol (paclobutrazol);(E)-1-(4-chlorophenyl)-4,-4-timethyl-2-(1,2,4-trizol-l-yl)l-penten-3-ol (uniconazole).
\end{abstract}

Effect of retardants on shoot growth (Expt. 1). One single-node, leaf bud cutting was planted in each 0.5-liter pot with a bark-free, peat-lite medium (Sunshine No. 1, Fisons Horticulture, Vancouver, B. C.) on 10 May 1991. It was misted for 2 weeks. The pots were placed on a greenhouse bench and received $380 \mu \mathrm{mol} \cdot \mathrm{m}^{-2} \cdot \mathrm{s}^{-1}$ maximum photosynthetic photon flux density (PPFD). Plants received weekly applications of $24 \mathrm{~N}-3.5 \mathrm{P}-13.3 \mathrm{~K}$ water-soluble fertilizer (Grace-Sierra Horticultural Products, Milpitas, Calif.) at $0.83 \mathrm{~g} \cdot$ liter $^{-1}$. On 7 July 1991, plants with five to six leaves received the following growing medium drench treatments: 1) uniconazole (500 mg.liter ${ }^{-1}$ microemulsion; Sumagic, Valent U. S. A., Walnut Creek, Calif.) at $0,0.05,0.10,0.15$, or $0.20 \mathrm{mg} /$ pot or 2) paclobutrazol (4000 $\mathrm{mg} \cdot$ liter $^{-1}$ suspension; Bonzi, Sandoz Crop Protection, Chicago) at $0,0.1,0.2,0.4$, or 1.0 $\mathrm{mg} /$ pot. The drench volume was $75 \mathrm{ml} /$ pot, which produced no leaching. Additional plants were given uniconazole foliar sprays at 0,25 , 50 , or $100 \mathrm{mg} \cdot$ liter $^{-1}$ or paclobutrazol foliar sprays at $0,50,100,150$, or $200 \mathrm{mg} \cdot$ liter $^{-1}$, respectively. Each plant received $\approx 12 \mathrm{ml}$ of retardant solution containing $0.025 \%$ Tween 20. The medium surface was protected to separate the effect of drench from foliar spray. The air was 35C during application. The uppermost leaf of each plant was labeled to
Golden pothos is a tropical vine native to southeastern Asia. It is the foliage species most favored by consumers in the United States (MacCubbin, 1991), and it is sold in large quantities by itself or in combinations (Florida Dept. of Agriculture, 1992). Golden pothos has long internodes. Foliar $\alpha-$ cylopropyl- $\alpha$-4-methoxyphenyl)-5pyrimidinemethanol (ancymidol, A-Rest) and butanedioic acidmono(2,2-dimethylhydrazide) (darninozide, B-Nine) applications controlled golden pothos stem elongation (Poole et al., 1985). Drench uniconazole applications, 0.1$0.4 \mathrm{mg} / 0.5$-liter pot, reduced stem growth while increasing individual leaf size and basal branching (Wang et al., 1992). How a retardant applied to stock plants affects subsequent cutting growth and how a foliar retardant application affects golden pothos growth during greenhouse production and in a consumer environment need to be evaluated.

Our objective was to determine golden pothos' growth response to growth retardants applied to the foliage or container medium and golden pothos' postharvest performance under interior conditions. We also determined the growth of cuttings collected from stock plants treated previously with growth retardants.

Received for publication 25 Feb. 1993. Accepted for publication 19 Sept. 1993. The cost of publishing this paper was defrayed in part by the payment of page charges. Under postal regulations, this paper therefore must be hereby marked advertisement solely to indicate this fact.

${ }^{1}$ Associate Professor.

${ }^{2}$ Technician II.
Table 1. The effect of paclobutrazol and uniconazole on golden pothos (Epipremnum aureum) growth following a spray or drench application 6 weeks after treatment.

\begin{tabular}{|c|c|c|c|c|c|c|}
\hline $\begin{array}{l}\text { Retardant } \\
\text { rate }\end{array}$ & $\begin{array}{c}\text { Stem } \\
\text { elongation } \\
(\mathrm{cm})\end{array}$ & $\begin{array}{c}\text { No. } \\
\text { new } \\
\text { leaves }\end{array}$ & $\begin{array}{c}\text { Total } \\
\text { new-leaf } \\
\text { area } \\
\left(\mathrm{cm}^{2}\right) \\
\end{array}$ & $\begin{array}{c}\text { No. } \\
\text { lateral } \\
\text { shoots }\end{array}$ & $\begin{array}{l}\text { Stem } \\
\text { diam } \\
(\mathrm{mm})\end{array}$ & $\begin{array}{c}\text { Shoot } \\
\text { fresh } \\
\text { wt } \\
\text { (g) }\end{array}$ \\
\hline \multicolumn{7}{|c|}{ Soil drench $(m g / p o t)^{z}$} \\
\hline \multicolumn{7}{|l|}{ Paclobutrazol } \\
\hline 0.00 & 48.2 & 7.4 & 393 & 0.0 & 5.5 & 30.3 \\
\hline 0.10 & 16.8 & 7.2 & 489 & 1.8 & 6.5 & 30.0 \\
\hline 0.20 & 15.0 & 6.6 & 504 & 1.0 & 6.8 & 30.3 \\
\hline 0.40 & 10.2 & 6.4 & 522 & 1.8 & 7.5 & 29.9 \\
\hline 1.00 & 5.8 & 5.8 & 471 & 2.6 & 7.6 & 26.5 \\
\hline Significance & $\mathrm{L}^{* *} \mathrm{Q}^{* *}$ & $\mathrm{~L}^{* *}$ & $\mathrm{Q}^{* *}$ & $\mathrm{~L}^{*}$ & $\mathrm{~L}^{* *} \mathrm{Q}^{* *}$ & NS \\
\hline \multicolumn{7}{|l|}{ Uniconazole } \\
\hline 0.00 & 51.1 & 7.2 & 447 & 0.0 & 5.8 & 35.0 \\
\hline 0.05 & 24.8 & 7.2 & 560 & 2.2 & 6.6 & 35.0 \\
\hline 0.10 & 15.0 & 7.0 & 522 & 3.6 & 6.5 & 33.3 \\
\hline 0.15 & 14.5 & 6.6 & 584 & 3.4 & 7.7 & 30.0 \\
\hline 0.20 & 11.2 & 6.6 & 592 & 4.6 & 7.3 & 32.0 \\
\hline Significance & $\mathrm{L}^{* *} \mathrm{Q}^{* *}$ & $\mathrm{~L}^{*}$ & $\mathrm{~L}^{*}$ & $\mathrm{~L}^{* *}$ & $\mathrm{~L}^{* *}$ & NS \\
\hline \multicolumn{7}{|c|}{ Foliar spray (mg.liter $\left.{ }^{-1}\right)^{y}$} \\
\hline \multicolumn{7}{|l|}{ Paclobutrazol } \\
\hline 0 & 51.0 & 7.6 & 462 & 0.0 & 6.0 & 35.9 \\
\hline 50 & 43.4 & 7.4 & 493 & 0.2 & 6.7 & 36.8 \\
\hline 100 & 34.0 & 7.2 & 482 & 0.2 & 6.8 & 34.2 \\
\hline 150 & 29.6 & 6.8 & 504 & 0.2 & 7.0 & 34.6 \\
\hline 200 & 28.1 & 7.6 & 564 & 0.4 & 6.9 & 37.3 \\
\hline Significance & $\mathrm{L}^{* *}$ & NS & $\mathbf{L}^{*}$ & NS & $\mathrm{L}^{* *}$ & NS \\
\hline \multicolumn{7}{|l|}{ Uniconazole } \\
\hline 0 & 46.1 & 7.2 & 396 & 0.0 & 5.9 & 31.0 \\
\hline 25 & 20.9 & 7.2 & 490 & 1.2 & 6.8 & 32.3 \\
\hline 50 & 10.2 & 6.6 & 410 & 3.0 & 7.4 & 24.7 \\
\hline 100 & 7.6 & 6.8 & 450 & 3.2 & 7.7 & 25.2 \\
\hline Significance & $\mathrm{L}^{* *} \mathrm{Q}^{* *}$ & NS & NS & $\mathrm{L}^{* *} \mathrm{Q}^{*}$ & $\mathrm{~L}^{* *} \mathrm{Q}^{*}$ & NS \\
\hline
\end{tabular}

${ }^{2}$ Ten-centimeter-square pots with a 0.5 -liter capacity; drench volume was $75 \mathrm{ml}$.

'Each plant received $\approx 12 \mathrm{ml}$ of the retardant solution with $0.025 \%$ Tween 20 .

ss, ${ }^{*}, *$ Linear $(\mathrm{L})$ or quadratic (Q) response nonsignificant at $\mathrm{a}=0.05$ or significant at $\alpha=0.05$ or 0.01 , respectively. 
determine subsequent stem growth. A single pot represented an experimental unit, and treatments were replicated 15 times in a randomized complete-block design. Each retardant and application method was arranged as a separate experiment because of the diverse rates.

Six weeks after the growth regulator treatment (21 and 22 Aug.), shoots of all plants in the first five replications were severed at the labeled node for stem elongation evaluation, largest-leaf area, new-leaf total area, and shoot fresh weight. An additional five replications of plants, with the uppermost new leaves labeled for determining future stem growth, were moved intact into rooms with $10 \mathrm{~h}$ of 25 $\mu \mathrm{mol} \cdot \mathrm{m}^{-2} \cdot \mathrm{s}^{-1} \mathrm{PPFD}$ from cool-white fluorescent lighting, $24 \pm 2 \mathrm{C}$ air, and $50 \%$ to $70 \%$ relative humidity. Plants were irrigated as needed with water from a reverse osmosis unit (water electrical conductivity $\approx 0.03 \mathrm{dS} \cdot \mathrm{m}^{-1}$ ) and fertilized biweekly at $0.42 \mathrm{~g} \cdot$ liter $^{-1}$. Plants were harvested after 10 weeks for stem elongation evaluation, new-leaf counts, second acropetal leaf area, total new-leaf area, and shoot fresh weight.

Production response. Drench and foliar applications of paclobutrazol and uniconazole were effective in suppressing stem elongation (Table 1). Although the number of new leaves produced was negatively affected by retardant drenches, most of the treated plants had a larger leaf area than the controls, the result of larger individual leaves. Both retardants have reduced leaf production in Brassaia actinophylla Endl. and Plectranthus australis R. Br., but increased leaf size of Syngonium podophyllum Schott (Wring and Blessington, 1990).

Uniconazole promoted the axillary buds on the lower nodes to develop into shoots, regardless of application method. However, application of paclobutrazol to the foliage did not result in significant basal budbreak (expressed as number of lateral shoots in Table 1). Foliar paclobutrazol or uniconazole applications at 50-200 or 25-100 mg.liter ${ }^{-1}$, respectively, did not affect the number of new leaves or shoot fresh weight. Both retardants, regardless of application method, produced thicker stems than the nontreated plants (Table 1).

Postproduction performance. After 10 weeks in an interior environment (16 weeks following treatment), plants treated with either retardant had less stem elongation than the controls; the reduction generally increased with the concentration rate (Table 2). Soil application of either retardant controlled stem elongation better than foliar sprays, although valid statistical comparison was not possible. Similarly, paclobutrazol drench applications were more effective than foliar applications in reducing stem growth in aluminum plant (Piles cadierei Gagnep. \& Guillaum) under interior conditions (Cox and Whittington, 1988). Unlike aluminum plants, golden pothos treated with either retardant did not develop leaf injury during the interior holding.

Despite a decrease in treated-plant leaf counts, total leaf area produced during the 10 weeks was unaffected because treated plants had larger leaves (Table 2). This feature in- creased the treated plants' aesthetic value. Shoot fresh weights generally were lower in the treated plants, possibly due to overall reduced plant growth (except in plants sprayed with paclobutrazol, which had unchanged fresh weights).

Table 2. Effect of paclobutrazol and uniconazole applied to golden pothos (Epipremnum aureum) plants as a foliar spray or soil drench during production on plant growth following 10 weeks under interior conditions. Plants were placed in the interior environment 6 weeks after treatment with a retardant.

\begin{tabular}{|c|c|c|c|c|c|}
\hline $\begin{array}{l}\text { Retardant } \\
\text { rate }\end{array}$ & $\begin{array}{c}\text { Stem } \\
\text { elongation } \\
(\mathrm{cm})\end{array}$ & $\begin{array}{c}\text { No. } \\
\text { new } \\
\text { leaves }\end{array}$ & $\begin{array}{c}\text { Second } \\
\text { leaf } \\
\text { area } \\
\left(\mathrm{cm}^{2}\right)\end{array}$ & $\begin{array}{c}\text { Total } \\
\text { new-leaf } \\
\text { area } \\
\left(\mathrm{cm}^{2}\right)\end{array}$ & $\begin{array}{c}\text { Shoot } \\
\text { fresh } \\
\text { wt } \\
\text { (g) }\end{array}$ \\
\hline \multicolumn{6}{|c|}{ Soil drench $(m g / p o t)^{z}$} \\
\hline \multicolumn{6}{|l|}{ Paclobutrazol } \\
\hline 0.00 & 58.6 & 7.8 & 68.3 & 527 & 40.6 \\
\hline 0.10 & 38.9 & 6.5 & 76.5 & 525 & 36.8 \\
\hline 0.20 & 16.5 & 5.3 & 95.4 & 485 & 29.9 \\
\hline 0.40 & 12.9 & 4.8 & 103.3 & 502 & 30.5 \\
\hline 1.00 & 14.1 & 4.7 & 103.4 & 472 & 30.4 \\
\hline Significance & $\mathrm{L}^{* *} \mathrm{Q}^{* *}$ & $L^{* *} Q^{* *}$ & $\mathrm{~L}^{* *} \mathrm{Q}^{* *}$ & $\mathrm{NS}^{--}$ & $\mathrm{L}^{* *}$ \\
\hline \multicolumn{6}{|l|}{ Uniconazole } \\
\hline 0.00 & 57.0 & 7.3 & 68.7 & 529 & 41.6 \\
\hline 0.05 & 19.8 & 5.2 & 91.5 & 492 & 30.5 \\
\hline 0.10 & 6.8 & 4.5 & 99.4 & 461 & 26.7 \\
\hline 0.15 & 8.0 & 4.5 & 115.4 & 514 & 31.3 \\
\hline 0.20 & 6.1 & 4.7 & 90.8 & 434 & 24.2 \\
\hline Significance & $\mathrm{L}^{* *} \mathrm{Q}^{* *}$ & $\mathrm{~L}^{* *} \mathrm{Q}^{* *}$ & $\mathrm{~L}^{* *} \mathrm{Q}^{* *}$ & NS & $\mathrm{L}^{* *}$ \\
\hline \multicolumn{6}{|c|}{ Foliar spray (mg.liter $\left.{ }^{-1}\right)^{y}$} \\
\hline \multicolumn{6}{|l|}{ Paclobutrazol } \\
\hline 0 & 66.0 & 8.0 & 68.8 & 519 & 40.7 \\
\hline 50 & 60.2 & 7.7 & 64.2 & 543 & 39.8 \\
\hline 100 & 53.0 & 7.3 & 72.6 & 553 & 40.7 \\
\hline 150 & 57.7 & 7.5 & 66.1 & 542 & 39.3 \\
\hline 200 & 40.0 & 6.2 & 73.9 & 488 & 34.0 \\
\hline Significance & $\mathrm{L}^{*}$ & $\mathrm{~L}^{* *}$ & NS & NS & NS \\
\hline \multicolumn{6}{|l|}{ Uniconazole } \\
\hline 0 & 58.2 & 7.7 & 64.0 & 501 & 36.9 \\
\hline 25 & 30.2 & 6.0 & 72.9 & 447 & 29.3 \\
\hline 50 & 19.9 & 5.0 & 79.2 & 421 & 26.0 \\
\hline 100 & 11.2 & 4.8 & 84.3 & 408 & 23.7 \\
\hline Significance & $\mathrm{L}^{* *} \mathrm{Q}^{* *}$ & $\mathrm{~L}^{* *} \mathrm{Q}^{* *}$ & $\mathrm{~L}^{*}$ & NS & $\mathrm{L}^{* *}$ \\
\hline \multicolumn{6}{|l|}{$\begin{array}{l}\text { Paclobutrazol vs. } \\
\text { uniconazole }\end{array}$} \\
\hline Significance & $* *$ & $* *$ & $*$ & $* *$ & $* *$ \\
\hline
\end{tabular}

${ }^{2}$ Ten-centimeter-square pots with a 0.5 -liter capacity; drench volume was $75 \mathrm{ml}$.

${ }^{y}$ Each plant received $\approx 12 \mathrm{ml}$ of the retardant solution with $0.025 \%$ Tween 20 .

Only the common rates in both retardants are used.

$*$,**, ${ }^{\text {NS }}$ Linear $(\mathrm{L})$ or quadratic (Q) response significant at $\alpha=0.05$ or 0.01 , or nonsignificant at $\alpha=0.05$, respectively.

Table 3. Growth of golden pothos (Epipremnum aureum) cuttings taken from stock plants treated with paclobutrazol or uniconazole. Cuttings were taken 6 weeks after treatment and harvested after 10 weeks of growth.

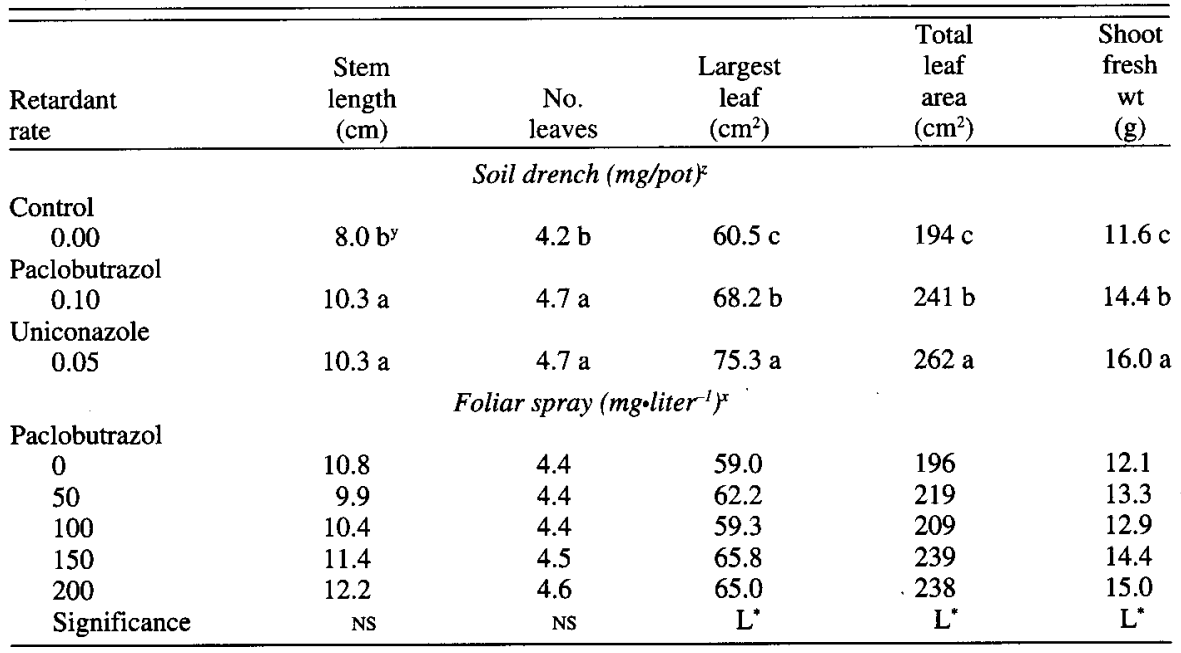

Ten-centimeter-square pots with a 0.5 -liter capacity; drench volume was $75 \mathrm{ml}$.

'Mean separation within columns and application method by Duncan's multiple range test at $\alpha=0.05$. 'Each plant received $12 \mathrm{ml}$ of the retardant solution with $0.025 \%$ Tween 20 .

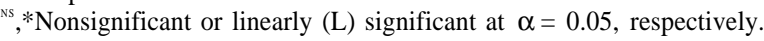


Effect of stock plantc growth retardant treatment on subsequent cutting performance (Expt. 2). Using the last five replications of Expt. 1, cuttings were collected from control plants and those that had received paclobutrazol and uniconazole soil drenches of 0.1 or 0.05 $\mathrm{mg} /$ pot, respectively, and foliar paclobutrazol applications at all concentrations $(0,50,100$, 150 , or $200 \mathrm{mg} \cdot$ liter $\left.^{-1}\right)$. These plants were chosen because other treatments resulted in shoots without adequate internodal length for cutting. Cuttings were collected from nodes above the basal fourth and below the uppermost fully expanded leaf node (Wang and Boogher, 1988), placed in a mist bed for 2 weeks, and grown under $420 \mu \mathrm{mol} \cdot \mathrm{m}^{-2} \cdot \mathrm{s}^{-1}$ maximum PPFD for 10 weeks. They were fertilized weekly at $0.83 \mathrm{~g} \cdot \mathrm{liter}^{-1}$, and evaluated for stem length, leaf count, largest-leaf area, total leaf area, and shoot fresh weight.

Cuttings collected from stock plants previously treated with a paclobutrazol or uniconazole soil drench $(0.1$ or $0.05 \mathrm{mg}$, respectively) produced shoots with longer stems, more and larger leaves, and heavier shoots than cuttings from nontreated plants (Table 3 ). These increases may have been the result of enhanced rooting (Davis, 1986) and/or better nutrient supply by the large parent leaves on cuttings taken from stock plants treated with a retardant (Table 1; Wang et al., 1992). Although foliar paclobutrazol applications to stock plants had marginal effects on stem length and no effect on leaf counts, it did result in larger leaves and heavier shoots than the controls.

\section{Conclusion}

These results demonstrate that uniconazole and paclobutrazol maybe used during production of pothos to restrict internodal elongation, increase leaf size, and improve plant quality in an interior environment. Under the conditions of this study, these retardants enhanced cutting growth.

\section{Literature Cited}

Cox, D.A. and F.F. Wittington. 1988. Effects of paclobutrazol on height and performance of aluminum plant in a simulated interior environment. HortScience 23:222.

Davis, T.D. 1986. Influence of triazole growth retardants on adventitious root formation in bean hypocotyl cuttings. Proc. Plant Growth Regulat. Soc. Amer. 13:217-223.

Florida Dept. of Agriculture. 1992. Foliage facts. January. Florida Dept. of Agriculture, Tallahassee.

MacCubbin, T. 1991. What the consumer really wants: Pothos. Fla. Foliage 17(2): 12-13.

Poole, R.T., C.A. Conover, A.R. Chase, and L.S. Osborne. 1985. Pothos production guide. Foliage Dig. 8(4):4-8.

Wang, Y.T. and T.M. Blessington. 1990. Growth of four tropical foliage species treated with paclobutrazol or uniconazole. HortScience 25:202-204.

Wang, Y.T. and C.A. Boogher. 1988. Effect of nodal position, cutting length, and root retention on the propagation of golden pothos. HortScience 23(2):347-349.

Wang, Y.T., K.H. Hsiao, and L.L. Gregg. 1992. Antitranspirant, water stress, and growth retardant regulate growth of golden pothos. HortScience 27:222-224. 